\title{
Avaliação do potencial de produção de sementes de acessos de trevo branco $^{1}$
}

\author{
Rodrigo Ramos Lopes², Lúcia Brandão Franke ${ }^{3}$, Miguel Dall'Agnol ${ }^{3}$, Fernanda Bortolini ${ }^{3}$ \\ 1 Pesquisa financiada com apoio da Coordenadoria de Aperfeiçoamento de Pessoal de Nível Superior (CAPES). \\ 2 Programa de Pós-graduação em Zootecnia, Faculdade de Agronomia, Universidade Federal do Rio Grande Sul. Bolsista CNPq. \\ ${ }^{3}$ Departamento de Plantas Forrageiras e Agrometeorologia da Faculdade de Agronomia/UFRGS, Caixa Postal 15100, CEP: 91501-970, \\ Porto Alegre/RS.
}

RESUMO - Este trabalho foi conduzido com o objetivo de avaliar o potencial de produção de sementes de 25 acessos da coleção básica de trevo-branco provenientes do Departamento de Agricultura dos Estados Unidos. Por meio de amostragens semanais realizadas entre 6/11/2003 e 10/3/2004, foram avaliadas as seguintes variáveis: número de inflorescências/planta, número de flores/inflorescência, número de inflorescências maduras/planta, número de legumes maduros/inflorescência, peso de mil sementes e rendimento de sementes/planta. O delineamento experimental utilizado foi o completamente casualizado, com os acessos arranjados individualmente em cinco repetições. O rendimento de sementes em trevo-branco é altamente influenciado pelo número de inflorescências por planta, pelo número de inflorescências maduras por planta e pelo peso de mil sementes. Os acessos 53, 2 e 20 destacam-se pela superioridade em relação aos demais $(7,68,19,79,58,3,15,75,64,50,33,13,59,38,28,80,54,29,31,23,22,27,65$ e 73) na produção de sementes. Os acessos 27, 65 e 73 não produzem sementes nas condições locais durante o primeiro ano de avaliação.

Palavras-chave: componentes do rendimento de sementes, número de inflorescências, peso de sementes

\section{Evaluation of the seed production potential of white clover accessions}

\begin{abstract}
This work was carried out to evaluate the potential of seed production of 25 accessions of the basic collection of white clover from the United States Department of Agriculture. Through weekly samplings performed from $11 / 6^{\text {th }} / 2003$ to $3 / 10^{\text {th }} / 04$ the following variables were analyzed: number of inflorescence/plant, number of flowers/ inflorescence, number of mature inflorescence/plant, number of mature legumes/inflorescence, weight of 1000 seeds, and seed yield/plant. It was used a complete randomized experimental design with the accessions individually arranged in five replications. Seed yield of white clover is highly affected by number of inflorescence/plant, number of mature inflorescence/ plant, and weight of 1000 seeds. The 53, 2 and 20 accessions differ from the others because of their superiority (7, 68, 19, $79,58,3,15,75,64,50,33,13,59,38,28,80,54,29,31,23,22,27,65$ and 73) of seed production. The accessions 27, 65 and 73 do not produce seeds in the local conditions during the first year of evaluation.
\end{abstract}

Key Words: components of seed yield, number of inflorescence, seed weight

\section{Introdução}

As leguminosas forrageiras de clima temperado, ou de produção hibernal, representam o grupo que causa maior impacto na produção animal, principalmente pela aceitação e qualidade da forragem produzida (Flores et al., 2004).

O Trifolium repens $L$. possui características que o tornam no mínimo adequado ao experimento, a saber: rusticidade, prolificidade, não exigência quanto às condições do solo e resistência ao inverno. Esta leguminosa foi introduzida no sul do Brasil para fins forrageiros e, como consequência, naturalizou-se em todo o planalto meridional (Lorenzi, 2000).

O trevo-branco apresenta um desenvolvimento floral que se caracteriza por um período longo de florescimento. As inflorescências emergem constantemente, podendo existir em um mesmo estolão, inflorescências em diversos estágios de desenvolvimento (Gibson \& Hollowell, 1966). Este comportamento floral afeta diretamente a produção de sementes, sendo o rendimento obtido na colheita sempre abaixo do potencial de produção da planta. 
A identificação do componente de rendimento de sementes que possui maior contribuição sobre a produtividade de sementes em trevo-branco é uma ferramenta importante, que pode auxiliar na definição do período crítico do ciclo de desenvolvimento em que é definido o rendimento de sementes da cultura. Com isso, podem-se adotar práticas de manejo que melhorem as condições de ambiente no momento em que será definido o principal componente do rendimento de sementes.

De acordo com Marshall (1994), os componentes que afetam o rendimento de sementes em $T$. repens incluem o número de inflorescências por unidade de área, número de flores/inflorescência, número de sementes/legume e o peso das sementes maduras. Cada um destes componentes é dependente de fatores ambientais, genéticos e de manejo. A capacidade de extensão do florescimento durante um período e, em particular, o número de inflorescências/ unidade de área são fatores importantes na determinação do potencial de rendimento de sementes de trevo-branco.

Visando obter informações adicionais destes acessos, o presente trabalho foi conduzido com o propósito de colher informações sobre a produção de sementes e componentes do rendimento de sementes de 25 acessos de trevo-branco, obtidos da coleção básica de trevo-branco do Departamento de Agricultura dos Estados Unidos.

\section{Material e Métodos}

Os componentes e o potencial de produção de sementes de 25 acessos obtidos da Coleção Básica de Trevo-branco, provenientes do Departamento de Agricultura dos Estados Unidos (USDA - United States Departament of Agriculture) e os acessos 79 (Cv. Grasslands Huia) e o acesso 80 (cv. Ladino Regal) (Tabela 1), foram avaliados durante uma estação de crescimento (2003/2004), por meio de amostragens semanais realizadas entre 6/11/2003 e $10 / 3 / 2004$.

O experimento foi alocado na Estação Experimental Agronômica da Universidade Federal do Rio Grande do Sul (EEA-UFRGS), no município de Eldorado do Sul - RS, localizada no km 47 da Rodovia BR 290. A EEA está localizada na região fisiográfica da Depressão Central, cujo clima é do tipo Cfa, subtropical úmido com verão quente, segundo a classificação de Köppen. De acordo com Bergamaschi et al. (2003), a precipitação total média anual na EEA situa-se em torno de $1440 \mathrm{~mm}$, com média mensal de $120 \mathrm{~mm}$. Os eventos meteorológicos registrados durante o período experimental foram obtidos na Estação Meteorológica do Departamento de Plantas Forrageiras e Agrometeorologia/UFRGS, localizada a cerca de $50 \mathrm{~m}$ da área experimental (Figura 1).
O solo da unidade experimental pertence à Unidade de Mapeamento São Jerônimo, classificado como Argissolo Vermelho distrófico típico - Pvd (Streck et al., 2008). De acordo com a análise do solo realizada em janeiro de 2003, o solo apresentava $\mathrm{pH}\left(\mathrm{H}_{2} \mathrm{O}\right)$ de 6,2; índice SMP igual a 6,6; 1,4 mg/L de fósforo; $81 \mathrm{mg} / \mathrm{L}$ de potássio; 1,8 de matéria orgânica; ausência de alumínio; $2,2 \mathrm{cmol}_{\mathrm{c}} / \mathrm{L}$ de cálcio e $1,3 \mathrm{cmol}_{\mathrm{c}} / \mathrm{L}$ de magnésio. O solo foi corrigido com $160 \mathrm{~kg} /$ ha de $\mathrm{P}_{2} \mathrm{O}_{5}$ sob a forma de superfosfato simples e $60 \mathrm{~kg} /$ ha de $\mathrm{K}_{2} \mathrm{O}$ sob a forma de cloreto de potássio.

O delineamento experimental utilizado foi o completamente casualizado, com os acessos arranjados individualmente em cinco repetições. Deste modo o experimento foi constituído de 135 unidades experimentais, correspondentes aos 27 acessos, e repetidos cinco vezes. O último corte foi efetuado no dia 27/10/2003, deixando um resíduo com altura aproximada de $3 \mathrm{~cm}$ do solo. Foram realizadas as seguintes observações: número de inflorescências/planta, número de flores/inflorescência, número de inflorescências maduras/planta, número de legumes maduros/inflorescência, percentagem de flores fecundadas, peso de 1000 sementes e rendimento de sementes/planta.

O número de inflorescências/planta foi determinado pela contagem semanal do número de inflorescências abertas de cada planta.

Para a determinação do número de flores/inflorescência, efetuou-se a retirada de duas inflorescências intactas tomadas ao acaso por planta e destas foi contado o número de flores para determinar o número médio de flores/ inflorescência.

O número de inflorescências maduras/planta foi determinado pela contagem semanal do número de inflorescências maduras de cada planta.

Para determinação do número de legumes maduros/ inflorescência, efetuou-se a retirada de duas inflorescências maduras intactas tomadas ao acaso por planta e destas foi contado o número de legumes maduros para determinar o número médio de legumes maduros/inflorescência.

A porcentagem de flores fecundadas foi determinada pela divisão do número de legumes que formaram sementes/ inflorescência pelo número máximo de flores/inflorescência.

Para determinação do peso de 1000 sementes, foram misturadas as sementes de todas as repetições de cada acesso e efetuou-se a pesagem de oito subamostras de 100 sementes, segundo os critérios estabelecidos pelas RAS (Brasil, 1992).

O rendimento de sementes/planta foi determinado através das inflorescências maduras que eram coletadas semanalmente, posteriormente secas em estufa a $30^{\circ} \mathrm{C}$ com 
Tabela 1 - Identificação, país em que foi obtido, área foliar, matéria seca e estado de melhoramento de vários acessos da Coleção Básica de Trevo-branco

\begin{tabular}{|c|c|c|c|c|c|}
\hline Acesso & $\begin{array}{c}\text { Identificação } \\
\text { no USDA* }\end{array}$ & $\begin{array}{l}\text { País em que } \\
\text { foi obtido }\end{array}$ & $\begin{array}{c}\text { Área } \\
\text { foliar }\left(\mathrm{cm}^{-2}\right)^{1}\end{array}$ & $\begin{array}{l}\text { Matéria seca } \\
\left(\mathrm{g}^{-1} / \text { planta }^{1}{ }^{2}\right.\end{array}$ & $\begin{array}{c}\text { Estado de } \\
\text { melhoramento }\end{array}$ \\
\hline 2 & SD & Israel & $9,54(1)$ & 69,8 & NC \\
\hline 3 & SD SRVR & Estados Unidos & $12,24(2)$ & 31,7 & Melhorado \\
\hline 13 & SD $M-40$ & Espanha & $6,45(1)$ & 29,3 & Incerto \\
\hline 15 & SD GRASSLANDS C2478 & Nova Zelândia & $6,59(1)$ & 21,8 & Melhorado \\
\hline 19 & SD NSL 085524 & Costa Rica & $4,49(1)$ & 33,9 & Material Cultivado \\
\hline 23 & SD BLANCA(R.V.P. La) & Bélgica & $6,70(1)$ & 16,9 & Cultivar \\
\hline 27 & SD CANADIAN LADINO & Canadá & $6,18(1)$ & 12,4 & Cultivar \\
\hline 28 & SD REELI & Austrália & $4,53(1)$ & 26,7 & Cultivar \\
\hline 29 & SD SELOMME & França & $5,15(1)$ & 23,6 & Tipo local \\
\hline 31 & SD NORTH AMERICAN LA & Estados Unidos & $8,41(1)$ & 18,6 & Cultivar \\
\hline 33 & SD & Irlanda & $8,23(1)$ & 32,7 & Incerto \\
\hline 58 & SD No. 10808 & Índia & $4,99(1)$ & 26,1 & Incerto \\
\hline 59 & SD No. 9981 & Líbano & $4,32(1)$ & 31,9 & Incerto \\
\hline 64 & SD No. 16236 & Suíça & $7,16(1)$ & 20,9 & Selvagem \\
\hline 65 & SD MORSO OTOFTE I & Dinamarca & $5,38(1)$ & 18,1 & Cultivar \\
\hline 68 & SD NLS 083034 & Jamaica & $4,28(1)$ & 25,4 & Incerto \\
\hline 73 & SD JBR II / 64 & Polônia & $6,34(1)$ & 27,0 & Cultivar \\
\hline 75 & SD 558 & Uruguai & $10,27(1)$ & 57,8 & Material Cultivado \\
\hline 79 & GRASSLANDS HUIA & Nova Zelândia & $5,85(1)$ & - & Cultivar \\
\hline 80 & Cv. Ladino Regal & Estados Unidos & $12,18(2)$ & - & Cultivar \\
\hline
\end{tabular}

NC = Não conhecido.

USDA = Departamento de Agricultura dos Estados Unidos.

${ }^{1}$ Bortolini et al., 2006.

(1) = tipo de folhas intermediárias

(2) = tipo de folhas grandes.

ventilação forçada e logo após trilhadas com o auxílio de um escarificador de sementes elétrico (1/3 HP - 1725 rpm) revestido com lixa ${ }^{\circ} 180$. O tempo de trilha durou cerca de 60 segundos para cada amostra. Logo após o material foi retirado do escarificador e passado em um conjunto de peneiras metálicas, retirando-se a fração mais grosseira. As sementes limpas foram pesadas em balança eletrônica com precisão de $0,0001 \mathrm{~g}$.

A produção de matéria seca foi avaliada através de dois cortes ( $1^{\circ}$ corte: 15 e 16/09/2003 e $2^{\circ}$ corte: 26 e 27/10/2003). O material cortado foi colocado individualmente em sacos de papel e em estufa a $60^{\circ} \mathrm{C}$, até atingir peso constante (Bortolini et al, 2006).

A área foliar foi realizada através da média de 12 folíolos por acesso, medidos com o auxílio de um planímetro ótico modelo LICOR 3100 (Bortolini et al, 2006).

Os dados foram submetidos à análise de variância através do programa estatístico GENES (Cruz, 2001) e, em caso de diferença significativa, as médias foram comparadas pelo teste de Scott-Knott a 5\% de probabilidade. Segundo Ferreira et al. (1999), o teste Scott-Knott é mais indicado para ensaios com grande número de tratamentos, pois

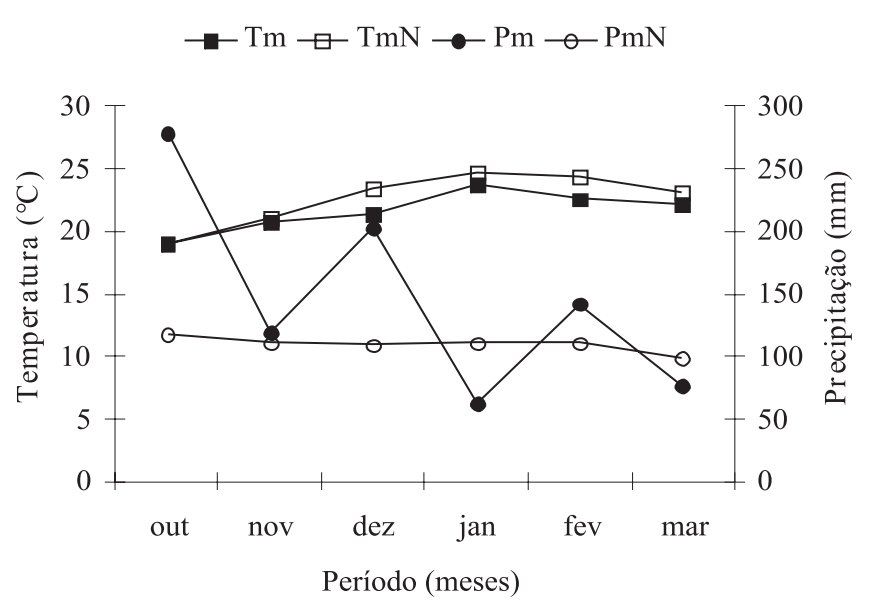

Figura 1 - Temperatura média mensal (Tm) e precipitação mensal (Pm) durante o período experimental e as normais para a região (temperatura média normal, TmN; precipitação mensal normal, PmN).

promove separação real de grupos de médias, eliminando a ambiguidade e auxiliando o pesquisador na discussão de seus resultados e na tomada de decisões.

A partir das médias (o acesso 65 foi excluído da análise por apresentar todas variáveis igual a zero) obtidas foi 
realizada análise de agrupamento com o auxílio do programa computacional NTSYSpc "Numerical Taxonomy and Multivariate Analysis System” versão 2.1 (Rohlf, 2000), estimando-se a distância entre os acessos de trevo-branco através da Distância Euclidiana. Para isso, foi gerada uma matriz de distância, a partir da qual foi realizada a análise de agrupamento dos acessos (módulo SAHN do NTSYS), utilizando-se o método da média das distâncias (UPGMA Unweighted Pair-Group Methodo using na Arithmetic Average) e, posteriormente, a construção do dendrograma.

A matriz de correlação residual de todas variáveis estudadas foi obtida através do procedimento PROC CORR (SAS, 2004), utilizando dezenove amostragens com cinco repetições de todos os acessos.

\section{Resultados e Discussão}

Através da análise de variância e do teste de comparação de médias, observou-se a separação dos acessos em três grupos distintos. Os acessos 20, 75 e 53 apresentaram maior número de inflorescências em relação aos demais $(\mathrm{P}<0,05)$, enquanto que os acessos 59, 3, 13, 54, 64, 15, 27, 31, 23, 80, 79, 29, 22, 73 e 65 foram os de menores valores (Tabela 2).

Observando os resultados dos acessos na variável número de inflorescências/planta, as médias podem ser consideradas baixas. Entretanto, Franke \& Nabinger (1991) encontraram valores semelhantes aos deste trabalho, que variaram entre 49,2 e 3,3 inflorescências/ $\mathrm{m}^{2}$. As prováveis causas destas diferenças no número de inflorescências são de ordem genética e climática como: fotoperíodo, temperatura e intensidade luminosa. E mesmo sob temperatura e comprimento do dia adequados, uma luminosidade insuficiente ainda poderia causar atraso ou até fracasso na indução floral (Zaleski, 1970). Segundo Flores et al. (2004), a precocidade de florescimento das populações está possivelmente vinculada às condições climáticas do local onde foram selecionados.

No caso do acesso 80, os resultados obtidos foram baixos (0,8 inflorescências/planta), mantendo-se bastante inferior aos demais. O mesmo comportamento deste acesso também foi observado por Franke \& Nabinger (1991), que obtiveram 3,3 inflorescências $/ \mathrm{m}^{2}$. Este fato pode ser considerado normal, pois segundo Annichiarico et al. (2001), em trabalhos com populações de trevo-branco coletadas no norte da Itália observaram que os tipos Ladinos florescem mais tarde que os outros materiais.

O acesso 20 foi o que apresentou maior número médio de inflorescências maduras/planta $(\mathrm{P}<0,05)$ (Tabela 2). De acordo com Hollington et al. (1989), o componente mais importante para obtenção de um satisfatório rendimento de sementes em trevo-branco é o número de inflorescências maduras no momento da colheita. Para maximização deste componente, o modelo do desenvolvimento floral deve ser claramente compreendido; diferenças varietais (genéticas) no padrão do desenvolvimento floral e sua interação com o ambiente devem ser levadas em conta (Marshall, 1994). O trevo-branco possui um comportamento cíclico, podendo apresentar vários picos de florescimento. Contudo, a contribuição de novas inflorescências, tende a diminuir com o tempo (Franke \& Nabinger, 1991).

O número de flores produzidas em cada inflorescência variou amplamente entre os acessos $(\mathrm{P}<0,05)$ (Tabela 3 ).

Esta amplitude da variação observada entre os acessos é uma característica deste componente da produção de sementes. O número de flores/inflorescência é uma variável fortemente influenciada pelo genótipo e pelo ambiente. Segundo Marshall (1994), dentre os fatores ambientais que podem influenciar este componente, destacam-se o fotoperíodo, intensidade de luz, temperatura, umidade do solo e a disponibilidade de nitrogênio no solo. Dos quatro acessos que apresentaram maiores médias no número de flores/inflorescência, três são trevos do tipo de folhas grandes (acessos 3, 50 e 80). Diversos trabalhos mencionam

Tabela 2 - Número total de inflorescências/planta e número de inflorescência maduras/planta de acessos de trevobranco

\begin{tabular}{|c|c|c|}
\hline Acessos & $\begin{array}{l}\text { Inflorescências } \\
\text { /planta (nô total) }\end{array}$ & $\begin{array}{c}\text { Inflorescências } \\
\left.\text { maduras/planta ( } \mathrm{n}^{\mathrm{o}}\right)\end{array}$ \\
\hline 20 & $64,9 a$ & $64,7 a$ \\
\hline 75 & $53,2 \mathrm{a}$ & $46,3 b$ \\
\hline 53 & $51,3 a$ & $47,0 \mathrm{~b}$ \\
\hline 68 & $38,2 b$ & $28,3 \mathrm{c}$ \\
\hline 2 & $33,2 b$ & $21,1 \mathrm{c}$ \\
\hline 7 & $31,6 b$ & $28,0 \mathrm{c}$ \\
\hline 50 & $30,5 b$ & $22,6 \mathrm{c}$ \\
\hline 58 & $30,2 b$ & $32,0 \mathrm{c}$ \\
\hline 19 & $28,6 b$ & $25,0 \mathrm{c}$ \\
\hline 33 & $23,4 b$ & $21,0 \mathrm{c}$ \\
\hline 38 & $22,4 \mathrm{~b}$ & $20,7 \mathrm{C}$ \\
\hline 28 & $22,3 b$ & $22,6 \mathrm{c}$ \\
\hline 59 & $19,8 \mathrm{c}$ & $16,9 d$ \\
\hline 3 & $16,9 \mathrm{c}$ & $11,5 d$ \\
\hline 13 & $14,5 \mathrm{c}$ & $12,4 d$ \\
\hline 54 & $13,7 \mathrm{C}$ & $7,9 d$ \\
\hline 64 & $8,0 \mathrm{c}$ & $6,0 \mathrm{~d}$ \\
\hline 15 & $6,3 c$ & $4,2 d$ \\
\hline 27 & $6,0 \mathrm{c}$ & $3,1 \mathrm{~d}$ \\
\hline 31 & $1,8 \mathrm{c}$ & $1,0 \mathrm{~d}$ \\
\hline 23 & $0,9 c$ & $0,4 d$ \\
\hline 80 & $0,8 \mathrm{c}$ & $0,4 \mathrm{~d}$ \\
\hline 79 & $0,9 \mathrm{c}$ & $1,0 \mathrm{~d}$ \\
\hline 29 & $0,7 \mathrm{c}$ & $0,7 d$ \\
\hline 22 & $0,7 \mathrm{C}$ & $0,4 d$ \\
\hline 65 & $0,0 \mathrm{c}$ & $0,0 \mathrm{~d}$ \\
\hline 73 & $0,0 \mathrm{c}$ & $0,0 \mathrm{~d}$ \\
\hline
\end{tabular}

Os valores seguidos pela mesma letra, na coluna, não diferem estatisticamente $(\mathrm{P} \leq 0,05)$ pelo teste Scott Knott. 
Tabela 3 - Número de flores/inflorescência, número de legumes maduros/inflorescência e porcentagem de flores fecundadas de acessos de trevo-branco

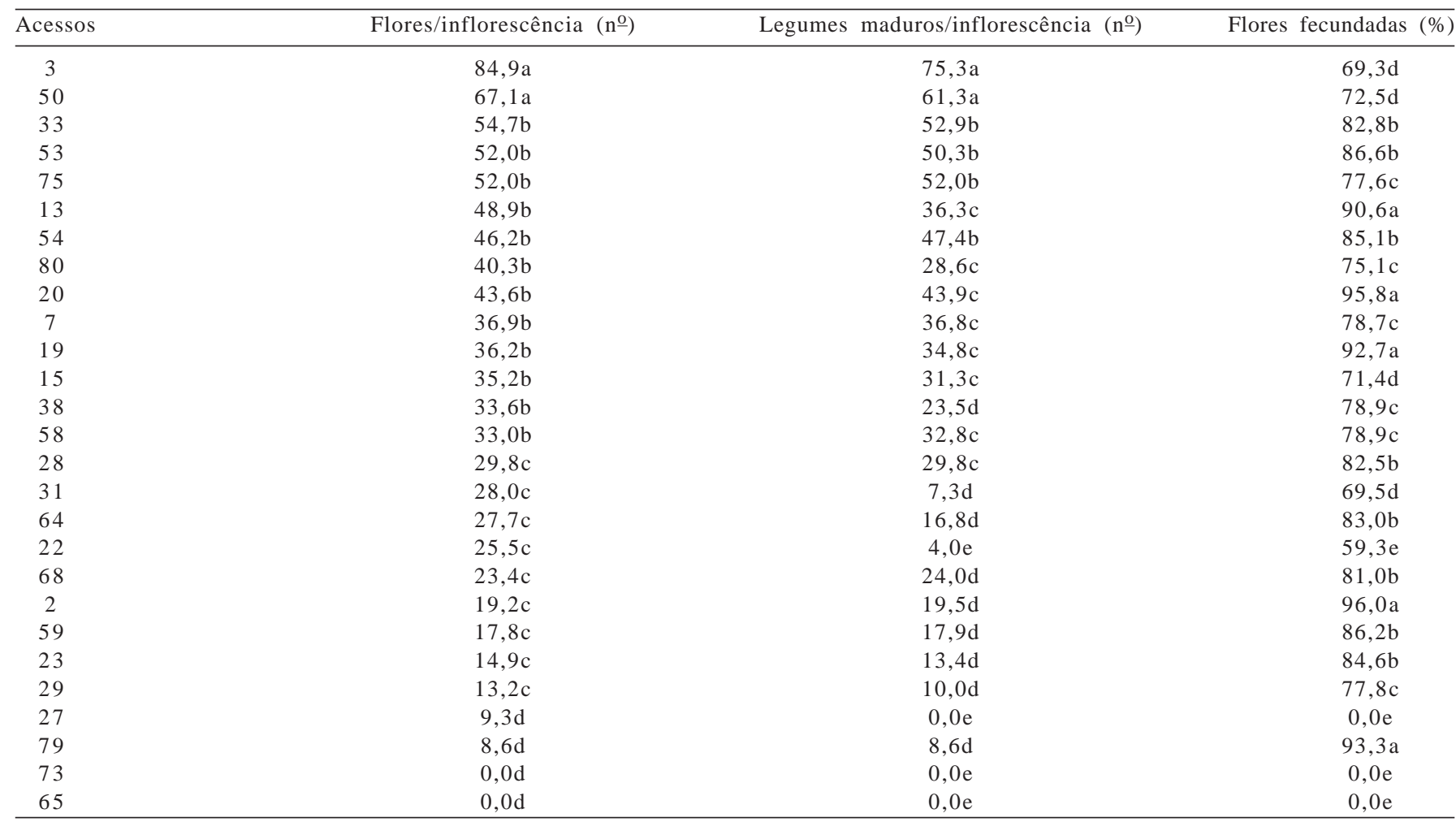

Os valores seguidos pela mesma letra, na coluna, não diferem estatisticamente $(\mathrm{P} \leq 0,05)$ pelo teste Scott Knott.

as diferenças no comportamento da espécie em função do tamanho de suas folhas. Segundo Williams et al. (1998), as diferenças entre tipos de trevo-branco são notáveis não apenas para o rendimento de sementes, mas também para a maior parte dos componentes de rendimento.

O componente número de legumes maduros/ inflorescência (Tabela 3), semelhante ao que ocorreu com o número de flores/inflorescência, variou amplamente entre os mesmos $(\mathrm{P}<0,05)$. Os acessos 3 , 33 e 80 foram os que mais se destacaram. O número de legumes maduros/inflorescência éuma variável dependente do número de flores/inflorescência, assim como da condição destas flores na época da polinização e fecundação e do número e eficiência dos insetos polinizadores.

Grande parte das leguminosas forrageiras de clima temperado (Trifolium spp.; Lotus spp.; Medicago spp.), utilizadas no Rio Grande do Sul, são de polinização cruzada. Dessa forma, para boa produção de sementes dessas espécies, há necessidade de satisfatória polinização entomófila (Camacho et al., 1999), para tanto o clima deve ser seco e ensolarado.

As flores fecundadas, ou seja, que se transformaram em legumes e formaram sementes, foram agrupadas em cinco grupos. Foram significativamente superiores $(\mathrm{P}<0,05)$ os acessos 2, 20, 79, 19, e 13 (Tabela 3). Essa superioridade pode estar relacionada à concentração de néctar nas flores, a qual determina a frequência das visitas, enquanto o volume determina a quantidade de abelhas coletoras que as visitarão (Free \& Willians, 1973).

A análise da variância revelou significância $(\mathrm{P}<0,05)$ entre os acessos para o peso de 1000 sementes (Tabela 4). Os acessos foram divididos em três grupos. Os acessos que apresentaram as sementes mais pesadas foram o 7, 68, 19, $79,58,3,15,75,64,50$, 53, e 33 (grupo superior), seguido pelos acessos 13, 2, 59, 38, 28, 80, 54, 20, 29, 31 e 23 (grupo intermediário). O peso de 1000 sementes no acesso 22 foi muito inferior aos demais, apresentando sementes muito pequenas. De acordo com Carvalho \& Nakagawa (2000), em geral, as sementes de maior tamanho foram bem nutridas durante o seu desenvolvimento, possuindo embriões bem formados e com maior quantidade de substâncias de reserva, sendo, consequentemente, as mais vigorosas. Annicchiarico (2001) encontrou alta correlação positiva entre peso de 1000 sementes e produção de sementes em populações naturais de trevo-branco. Assim, essa característica, dependendo da sua variabilidade em determinada população, pode mostrar-se significativa na determinação do rendimento de sementes.

O rendimento médio de sementes mostrou que os acessos 53, 20 e 2 foram superiores aos demais. Em um grupo 
Tabela 4 - Peso de 1000 sementes e rendimento de sementes por planta de acessos de trevo-branco

\begin{tabular}{ccc}
\hline Acessos & $\begin{array}{c}\text { Peso de mil } \\
\text { sementes(g-1/planta) }\end{array}$ & $\begin{array}{c}\text { Sementes/ } \\
\text { planta(g-1/planta })\end{array}$ \\
\hline 7 & $0,58 \mathrm{a}$ & $0,57 \mathrm{~b}$ \\
68 & $0,56 \mathrm{a}$ & $0,62 \mathrm{~b}$ \\
19 & $0,56 \mathrm{a}$ & $0,37 \mathrm{c}$ \\
79 & $0,55 \mathrm{a}$ & $0,09 \mathrm{c}$ \\
58 & $0,54 \mathrm{a}$ & $0,69 \mathrm{~b}$ \\
3 & $0,54 \mathrm{a}$ & $0,51 \mathrm{~b}$ \\
15 & $0,53 \mathrm{a}$ & $0,16 \mathrm{c}$ \\
75 & $0,53 \mathrm{a}$ & $0,44 \mathrm{~b}$ \\
64 & $0,53 \mathrm{a}$ & $0,34 \mathrm{c}$ \\
50 & $0,53 \mathrm{a}$ & $0,30 \mathrm{c}$ \\
53 & $0,52 \mathrm{a}$ & $1,14 \mathrm{a}$ \\
33 & $0,52 \mathrm{a}$ & $0,46 \mathrm{~b}$ \\
13 & $0,51 \mathrm{~b}$ & $0,39 \mathrm{c}$ \\
2 & $0,50 \mathrm{~b}$ & $0,90 \mathrm{a}$ \\
59 & $0,49 \mathrm{~b}$ & $0,19 \mathrm{c}$ \\
38 & $0,49 \mathrm{~b}$ & $0,17 \mathrm{c}$ \\
28 & $0,49 \mathrm{~b}$ & $0,49 \mathrm{~b}$ \\
80 & $0,49 \mathrm{~b}$ & $0,04 \mathrm{c}$ \\
54 & $0,49 \mathrm{~b}$ & $0,09 \mathrm{c}$ \\
20 & $0,48 \mathrm{~b}$ & $0,94 \mathrm{a}$ \\
29 & $0,48 \mathrm{~b}$ & $0,05 \mathrm{c}$ \\
31 & $0,47 \mathrm{~b}$ & $0,09 \mathrm{c}$ \\
23 & $0,43 \mathrm{~b}$ & $0,04 \mathrm{c}$ \\
22 & $0,14 \mathrm{c}$ & $0,03 \mathrm{c}$ \\
27 & $-\mathrm{x}-$ & $-\mathrm{x}-$ \\
65 & $-\mathrm{x}-$ & $-\mathrm{x}-$ \\
73 & $-\mathrm{x}-$ & $-\mathrm{x}-$ \\
\hline
\end{tabular}

Os valores seguidos pela mesma letra, na coluna, não diferem estatisticamente $(\mathrm{P} \leq 0,05)$ pelo teste Scott Knott. intermediário, foram agrupados os acessos 58, 68, 7, 3, 28, 33 , e 75 , sendo o restante dos acessos $(13,19,64,5059,38$, 15, 54, 79, 31, 29, 80, 23 e 22) os de menores valores. No estado do Rio Grande do Sul, os rendimentos de sementes variam de 189,6 kg/ha no primeiro ano e $241 \mathrm{~kg} / \mathrm{ha}$ no segundo ano de produção. A produtividade média no Uruguai obtida por produtores sementeiros, ou seja, cultivos com propósito especifico de colher sementes de trevobranco é de $112 \mathrm{~kg}$ de sementes/ha com variações entre 30 a $240 \mathrm{~kg} / \mathrm{ha}$ (Melo \& Barros, 2005).

O maior rendimento de sementes dos acessos 20 e 53 vem a corroborar os resultados observados no número de inflorescências/planta e número de inflorescências maduras/ planta. $\mathrm{O}$ alto potencial de rendimento pode ser relacionado a uma vigorosa produção de inflorescências em um curto intervalo de tempo, resultando uma proporção acima da média de inflorescências maduras na colheita. De acordo com Zaleski (1970), além da determinação do número de inflorescências por unidade de área, o tamanho das sementes também foi um dos principais fatores que contribuíram para o rendimento de sementes de trevo-branco.

De acordo com a análise de agrupamento, a distância média entre os 26 acessos analisados foi de 6,53, variando de 1,35 a 12,02 (Figura 2). O dendrograma foi dividido no ponto de distância média e resultou em dois grupos, onde

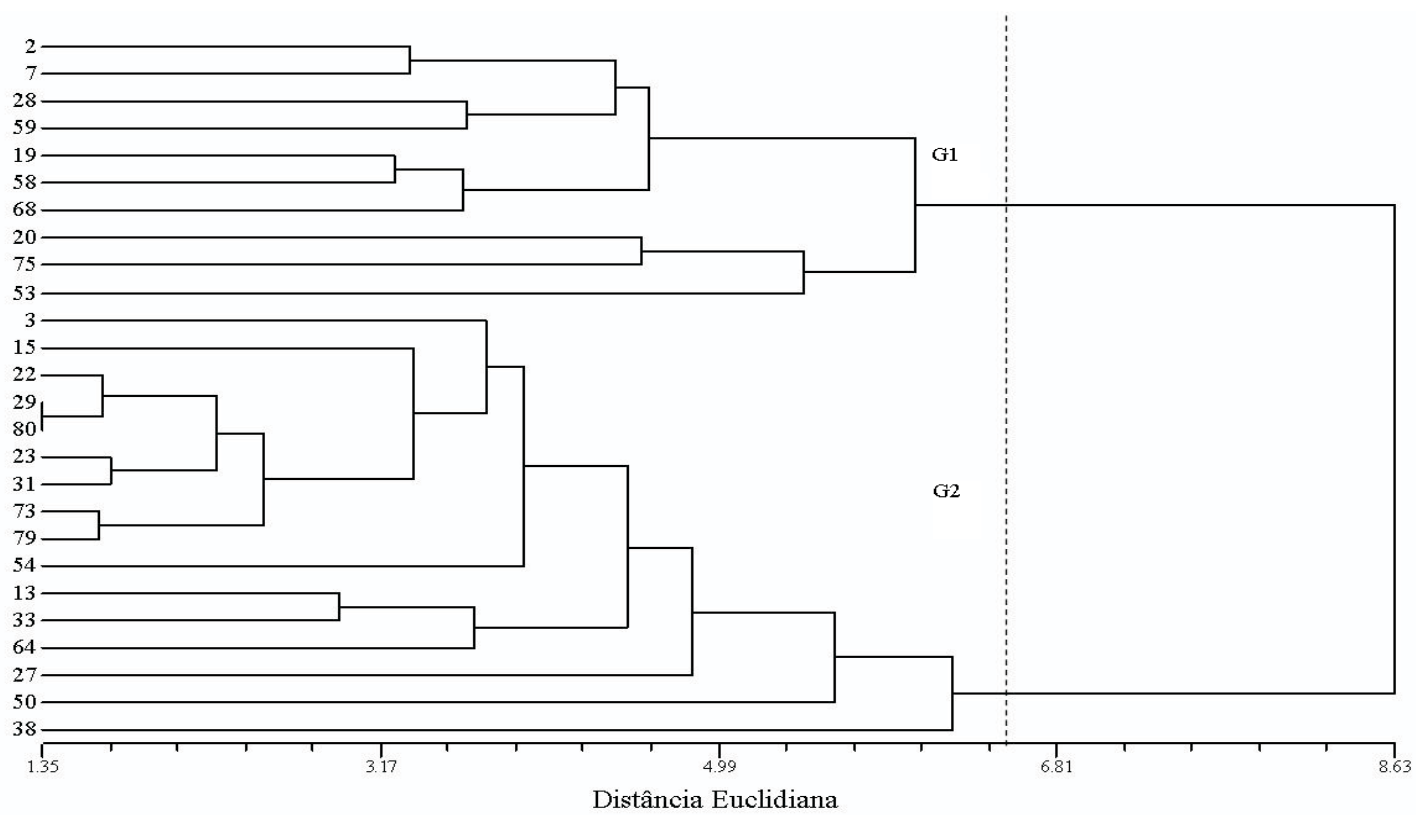

Figura 2 - Padrão de dissimilaridade, estabelecido pelo método das ligações médias (UPGMA), com base na distância Euclidiana, para acessos da Coleção Básica de trevo-branco. 
o primeiro grupo (G1) apresentou 11 acessos e o segundo grupo (G2) foi formado por 16 acessos. O acesso mais divergente foi o 20 (material melhorado do Uruguai) em relação aos acessos 3 (12,02 de divergência), 31 (11,54 de divergência), 80 (11,38 de divergência), 22 (11,28 de divergência) e 29 (11,14 de divergência). Em contrapartida, o menor índice de distância $(1,35)$ foi verificado entre os acessos 29 (tipo local proveniente da França) e o 80 (cultivar Ladino Regal proveniente dos Estados Unidos) indicando grande similaridade entre esses dois acessos de diferentes estados de melhoramento e origens geográficas, os quais se encontram no maior grupo (G2).

Os resultados observados demonstram a eficiência do método UPGMA em agrupar genótipos similares. Estes agrupamentos mostram que a origem geográfica não reflete, necessariamente, a diversidade genética, pois cultivares de diferentes regiões foram incluídas dentro de um mesmo grupo. Isso evidencia que a divergência genética nas cultivares está relacionada aos genes que as mesmas possuem (Silva, 1999). Segundo Upadhyay \& Murty (1970), a deriva genética e a seleção em diferentes ambientes podem causar maior divergência que a distância geográfica.

A análise de correlação simples apresentou significância de $1 \%(\mathrm{P}<0,01)$ pela estatística t (Tabela 5).

Observando os resultados, verifica-se alta correlação entre o número de inflorescências/planta e o rendimento de sementes/planta, assim como entre o número de inflorescências maduras/planta e o rendimento de sementes/ planta, ambas altamente significativas. Isto evidencia a importância destes componentes na determinação do rendimento de sementes confirmando inferências de Clifford (1980), de que o número de inflorescências por área é o maior componente do rendimento de sementes em trevo branco, e de Lopes \& Franke (2009), que apontam o número de inflorescências maduras como a principal variável a influenciar o rendimento de sementes em trevo-branco.

Tabela 5 - Correlações simples entre as variáveis avaliadas em acessos de uma coleção de trevo-branco

\begin{tabular}{lcccccc}
\hline & NIP & NIM & NFI & NLI & PMS & \multicolumn{1}{c}{ RSP } \\
\hline NIP & - & $0,99 * *$ & $-0,98^{* *}$ & $-0,98^{* *}$ & $0,98^{* *}$ & $0,98^{* *}$ \\
NIM & & - & $-0,96^{* *}$ & $-0,96 * *$ & $0,95 * *$ & $0,96 * *$ \\
NFI & & - & $0,99 * *$ & $-0,99 * *$ & $-0,99 * *$ \\
NLI & & & & - & $-0,98^{* *}$ & $-0,98 * *$ \\
PMS & & & & & - & $0,99 * *$ \\
RSP & & & & & & -
\end{tabular}

NIP = número de inflorescências por planta; NIM = número de inflorescências maduras por planta; NFI = número de flores/inflorescência; NLI = número de legumes maduros/inflorescência; PMS = peso de 1000 sementes; RSP = e rendimento de sementes/planta.

** Significativo a $1 \%$ de probabilidade pelo teste $t(\mathrm{P} \leq 0,01)$.
Também se evidenciou que com maior número de inflorescências/planta ocorre o efeito compensatório sobre o número de flores/inflorescências, conforme relatam Franke \& Nabinger (1991), causado pela competição por nutrientes na fase de diferenciação floral. Outra correlação importante foi a verificada entre o peso de 1000 sementes, indicando que quanto mais pesadas são as sementes produzidas, maior o rendimento de sementes.

\section{Conclusões}

Os acessos 53, 2 e 20 destacam-se pela superioridade na produção de sementes em relação aos demais $(7,68,19$, $79,58,3,15,75,64,50,33,13,59,38,28,80,54,29,31,23,22$, 27, 65 e 73). Os acessos 27, 65 e 73 não produzem sementes nas condições locais. Em análise de agrupamentos, é evidenciada a diversidade entre os grupos, explicada, em parte, pelo fato de que a diversidade genética não está correlacionada à diversidade geográfica, fato confirmado pela existência de acessos de origens geográficas diferentes, classificados no mesmo grupo de divergência genética. O rendimento de sementes em trevo-branco é altamente influenciado pelo número de inflorescências/planta, número de inflorescências maduras/planta e peso de 1000 sementes.

\section{Referências}

ANNICHIARO, P.; COLLINS, R.P.; FORNASIER, F. Variation in cold tolerance and spring growth among Italian white clover populations. Euphytica, v.122, n.1, p.407-416, 2001.

BERGAMASCHI, $\mathrm{H}$. Clima da estação experimental da UFRGS (e região de abrangência). Porto Alegre: UFRGS, 2003. 78p.

BORTOLINI, F.; DALL'AGNOL, M.; SCHIFINO-WITTMANN, M.T. et al. Caracterizações morfológica e agronômica e divergência genética em germoplasma de trevo-branco. Revista Brasileira de Zootecnia, v.35, n.4, p.1601-1610, 2006.

BRASIL. Ministério da Agricultura e Reforma Agrária. Regras para análise de sementes. Brasília: SNDA/DNDV/CLAV, 1992. 365p.

CAMACHO, J.C.B.; MONKS, P.L.; SILVA, J.B. A polinização entomófila na produção e qualidade germinativa de sementes de trevo vesiculoso (Trifolium vesiculosum Savi) cv. embrapa28 "Santa tecla". Revista Brasileira de Agrociência, v.5, n.2, p.114-119, 1999.

CARVALHO, N.M.; NAKAGAWA, J. Sementes: Ciência, tecnologia e produção. 4.ed. Jaboticabal: FUNEP, 2000. 588p.

CLIFORD, P.T.P. Research in white clover seed production. Palmerston North: New Zealand Grassland Association, 1980 p.64-67. (Grassland Research and Practice Series, 1).

CRUZ, C.D. Programa Genes: Versão Windows; aplicativo computacional em genética e estatística. Viçosa, MG: Universidade Federal de Viçosa, 2001. 285p.

FERREIRA, D.F.; MUNIZ, J.A.; AQUINO, L.H. Comparações múltiplas em experimentos com grande número de tratamentos - utilização do teste Scott-Knott. Ciência e Agrotecnologia, v.23, n.3, p.745-752, 1999.

FLORES, R.A.; SHEFFER-BASSO, S.M.; DALL'AGNOL, M. Caracterização morfofisiológica de genótipos de trevo branco. Revista Brasileira de Agrociência, v.8, n.1, p.21-28, 2004. 
FRANKE, L.B.; NABINGER, C. Dinâmica do florescimento de cinco cultivares de trevo branco. Pesquisa Agropecuária Brasileira, v.26, n.9, p.1475-1485, 1991.

FREE, J.B.; WILLIANS, I.H. The pollination of hybrid kale (Brassica oleracea L.). Journal Agricultural Science, v.81, p.557-59, 1973.

GIBSON, P.B.; HOLLOWELL, E.A. White clover. Washington, D.C.: USDA, 1966. 33p. (Agriculture Handbook, 314).

LOPES, R.R.; FRANKE, L.B. Análise de trilha dos componentes do rendimento de sementes de trevo-branco. Revista Brasileira de Zootecnia, v.38, n.10, p.1865-1869, 2009.

HOLLINGTON, P.A.; MARSHALL, A.H.; HIDES, D.H. Effect of seed crop management on potential seed yield of contrasting white clover varieties. II. Seed yield components and potential seed yield. Grass Forage Science, v.44, n.2, p. 189-193, 1989.

LORENZI, H. Plantas daninhas do Brasil. 3.ed. São Paulo: Plantarum 2000. 438p.

MARSHALL, A.H. Seasonal variation in the seed yield components of white clover (Trifolium repens). Plant Varieties and Seeds, v.7, p.97-105, 1994.
MELO, P.T.B.S.; BARROS, A.C.S.A. Situação da produção de sementes de trevo branco (Trifolium repens L.), cornichão (Lotus corniculatus L.) e lotus anual (Lotus subbiflorus Lag.) no Rio Grande do Sul. Revista Brasileira de Agrociência, v.11, n.1, p.13-88, 2005.

STATISTICAL ANALYSIS SYSTEM - SAS. SAS OnlineDoc. Version 9.1.3. Cary: SAS Institute, 2004. (CD-ROM).

STRECK, E.V.; KÄMPF, KÄMPF, N.; DALMOLIN, R.S.D. et al. Solos do Rio Grande do Sul. 2.ed. Porto Alegre: EMATER/ RS, UFRGS, 2008. 222p.

WILLIAMS, T.A.; ABBERTON, M.T.; THORNLEY, W.J. et al. Evaluation of seed production potencial in white clover (Trifolium repens L.) varietal improvement programmes. Grass and Forages Science, v.53, n.2, p.197-207, 1998.

ZALESKI, A. White Clover in Seed Production. In: SYMPOSIUM ON WHITE CLOVER RESEARCH, 1969, Belfast. Proceedings... Hurley: The British Grassland, Society, 1970. p.147-54. 